\title{
Behavior of the Global Oil Market (1995-2008) as Described by a System Dynamics Model*
}

\author{
María de la Fe López-Domínguez** \\ Sary Leuy-Carciente*** \\ José Contreras**** \\ Pedro César Paiva-Mata*****
}

\begin{abstract}
Energy largely determines the characteristics of the global economy, hence the importance of fully understanding the behavior of the oil market in its current geo-economic and political environment. Starting from the basic relations of the global oil market and their interactions with macroeconomic variables, a nonlinear dynamic, structural and systemic model for this market is developed, which simulates the price, production and consumption of oil, and the accumulation of inventories. Model tests show satisfactory performance in the simulation of the known past in a medium-term horizon, 1995-2008. A sensitivity study performed for the same period yield some interesting conclusions about the behavior of the global oil market, such as the irrelevance of the structural factors in the soaring rise in oil prices in 2008.
\end{abstract}

Keywords: Oil market. Simulation model. System dynamics.

JEL Classification: C63; C67; Q47.

\footnotetext{
* The authors wish to express their acknowledgement to the Central Bank of Venezuela (Banco Central de Venezuela, BCV), in particular to its Department of Economic Research, for their support to this work by inviting author María de la Fe López to develop part of her doctoral work at BCV as a guest researcher. The research reported in this paper is an integral part of the aforementioned doctoral work, under the guidance of Dr. Sary Levy-Carciente. Also, the authors are grateful to Dr. Klaus Jaffe, for his encouragement and insightful comments and suggestions.

** Universidad Central de Venezuela, Faculty of Economic and Social Sciences, Doctorate in Social Sciences, Caracas, Venezuela.E-mail:mlopez@usb.ve

*** Universidad Central de Venezuela, Dean of Economic and Social Sciences' Faculty, Caracas, Venezuela.E-mail: saryle@yahoo.com

**** Banco Central de Venezuela, Caracas, Venezuela. E-mail: joscontr@bcv.org.ve

***** Universidad Simón Bolívar, Caracas, Venezuela. E-mail: ppaiva@usb.ve
} 


\section{Introduction}

\subsection{Aim of the Work}

Econometric models base their operation in the representation of the statistical behavior of observed data within a specific time frame; thus, they lack the necessary information to simulate events not very similar to those occurred within that particular time frame, as might happen in the future. In turn, system dynamics is a paradigm suited for the modeling of social phenomena, based on considerations of accumulation of flow variables into level ones, a concept that necessarily entails compliance with conservation laws that may be applicable to metaphors relating social, economic or financial concepts to the material world where those laws are valid. Thus, the information contained in a model of this type is not confined to a specific time frame, because it comes from the material reality on which the behavior of the phenomenon is based.

The mainstream in global oil market modeling consists of empirical econometric models of structural or financial type, and although system dynamics has been used extensively for modeling various types of markets, the literature reports very few attempts to specifically model the global oil market using this paradigm.

In the assumption that an econometric representation could improve its overall performance if it worked embedded into an environment capable of taking into account the material reality of the agents of the market, this paper proposes a hybrid dynamic-econometric model for the global oil market, based on system dynamics, with feedback loops into which the behavior of individual market agents is simulated in part by using econometric representations. A sensitivity study performed on a hybrid dynamic model of this kind might shed light on the dynamics of the complex interrelationships between the various actors and factors in the global oil market. The authors of this paper were not able to find in the literature an attempt to model the global oil market through such a combination of econometric representations with system dynamics, and in this sense this paper aims to contribute to this important topic.

\subsection{Mainstream in the Global Oil Market Modeling}

Geo-political economics, and the Global Oil Market (GOM) as one of its determining agents, have been the subject of intense academic and professional interest, and the literature related to their modeling is very extensive. Fortunately, recent works (MOHADDES 2006; MANERA et al. 2007; FATTOUH 2007, among others) summarize reviews of the related literature, thus facilitating the collection, 
classification and comparison of the knowledge available up to date in the field. From this, it seems clear that the GOM modeling involves two major approaches: the theoretical and the empirical.

Theoretical models are based on ideal relations between factors that influence the market, according to economic and financial theories. The immediate practical application of these models is usually limited, given an assumed ideal behavior, which more often than not obviate the consideration of multiple real factors which concur in practice. These models attempt to simulate the behavior of the market under ideal theoretical conditions, to try to assess, for example, the macroeconomic consequences arising from oil price shocks (CAMPOLMI, 2008; BODENSTEIN; ERCEG; GUERRIERI, 2007), or the nature of the behavior of market factors (LIN, 2008).

In turn, empirical models are based on observation and experimentation, and their predictive usefulness is based on the assumption that what has happened in the past will happen in the future if the circumstances are the same. The reliability of these models depends on the database used during their development, i.e. the quality of observation and/or experimentation. These models are generally obtained by statistical procedures of curve fitting, and/or linear or multiple regression, depending on the type and/or the number of variables or factors considered.

An empirical model may be financial or structural. Financial models are focused, for example, on the relationship between variables such as spot price and crude oil futures, acting the latter as the explanatory factor of the former (PINDYCK, 1999; CHANTZIARA; SKIADOPOULOS, 2008). In turn, structural models are based on economics fundamentals of the oil market, related to supply and demand. In both cases the models depend on explanatory variables, different from prices, but that "explain" them. A financial type of empirical model involves time series, such as first-order autoregressive models (PINDYCK, 1999), or those of "random walk".

Most econometric models of the GOM are linear forms reduced to a single equation, with some outstanding exceptions such as those of the models of Dées et al. (2007) and Moshiri and Fouroutan (2006). The first proposes a structural model of multiple equations that considers the demand, OPEC production (pricing rule, both cooperative and non-cooperative) and nonOPEC production as endogenous variables, while the second proposes a model of a single nonlinear equation, the parameters of which are estimated by a neural network learning.

Fattouh (2007) classifies GOM models for the estimation of long term prices in structural (competitive frame of supply and demand), nonstructural (with emphasis in non-renewable petroleum resource depletion) and informal (also structural, based on explanatory variables related to economic, geopolitical and incidental factors that affect supply and demand and thus affect prices in certain contexts). Non-structural models are based on the rule of Hotelling (Hotelling's Rule states that the net price -for the competitive case- or the net marginal return -for the non competitive or monopolistic case- of the marginal cost of 
extraction must grow at the rate of interest. In other words, the optimal extraction path must be such that the price of underground crude oil should grow over time at the rate of interest, even in the absence of demand information). In turn, Mohaddes (2006) seems to share criteria with Fattouh, classifying models in those informal (competitive and non-competitive) and those based on the rule of Hotelling. Both authors highlight the limitations of the Hotelling rule; Mohaddes reports that the principle has no empirical support, while Fattouh indicates that models based on the Hotelling rule (oil depletion) can not describe oil prices behavior in the real world. Consequently, reliability is suggested only for structural, financial and time series models. The structural models are of regressive nature (linear or multiple), while time series are purely autoregressive. Finally, some authors conclude that there is no consensus in the literature about which model to use for oil prices prediction purposes, and that findings vary according to the models, time periods considered, and the frequency of the data.

Facts seem to confirm the shortcomings of the available models: none was able to predict the magnitude of the oil price increase occurred in 2006 and 2007, and continued in 2008, well above 100 U.S. $\$ /$ barrel, until the outbreak of the subprime crisis. This may be a symptom of the lack of something essential and crucial in the conception and design of models for the GOM.

Financial and time series models, or structural models? Because of the absence of economic explanatory variables, financial and time series models are insensitive to environmental factors that affect the behavior of prices. This is confirmed when reviewing the model of Pindyck (1999). Empirically its validity is confirmed, but only if a factor as important as the OPEC is not considered (MANERA et al., 2007), thus leading to unreasonable future price declines. Similarly, Chantziara and Skiadopoulo (2008) have shown the predictive narrowness of the financial models, and the necessity to consider additional factors, when they found that the main components of the daily fluctuations of the oil future prices have little predictive power, both within the observed data and outside it, let alone an accurate prediction of instant prices.

Of the models proposed in the literature, those of structural type are the ones that allow the consideration of real economic factors affecting the markets; such factors are, by nature, adaptable to the systemic paradigm. This is less easy for financial models and time series, given the absence of explanatory variables capable of relating prices with real factors implicit in the concepts of demand and supply.

\subsection{System Dynamics and the Global Oil Market Modeling}

The GOM can be seen as a system, subject to impacts of supply and demand, and responding with changes in oil prices. Since interactions between elements of the market are usually bi-directional, the market will as well respond to price 
shocks with variations in the supply-demand equilibrium. These characteristics seem to make the problem particularly adaptable to the dynamic system approach.

Although the fundamental rules of systems analysis are generally valid for all systems, they may be applied using different methodologies, some of them specifically oriented to the study of socio-economic phenomena, such as system dynamics (FORRESTER, 1972). These specific methodologies are based in the essential distinction between two types of variables, level variables and flow variables, and provide appropriate elements to build models that correctly describe systems internally connected by uni, multi or bi-directional relations, with feedback loops derived from the nonlinear character normally present in real world problems. The strength of this kind of methodology lies in its ability to easily build up complex models from simple blocks, focusing on specific areas of reality, and capable of discovering the consequences of the implementation of certain policies (LAGARDA; ALONSO, 2001).

From the above, system dynamics seems to be a suitable tool for the modeling of the dynamic and complex nature of the GOM. Reviewed literature shows little effort in this direction, and this work aims to modestly contribute to this effect.

\section{Methodology: Model Description}

\section{2.l Agents of the Model}

A dynamic model of the GOM is proposed, the operation of which is based on the classic market theory that describes the interrelationships between supply, demand and price (Figure 1). For the purposes of the model, the term supply is identified with the global oil production, demand with global consumption, and price with the reference price of a crude benchmark (i.e. WTI).

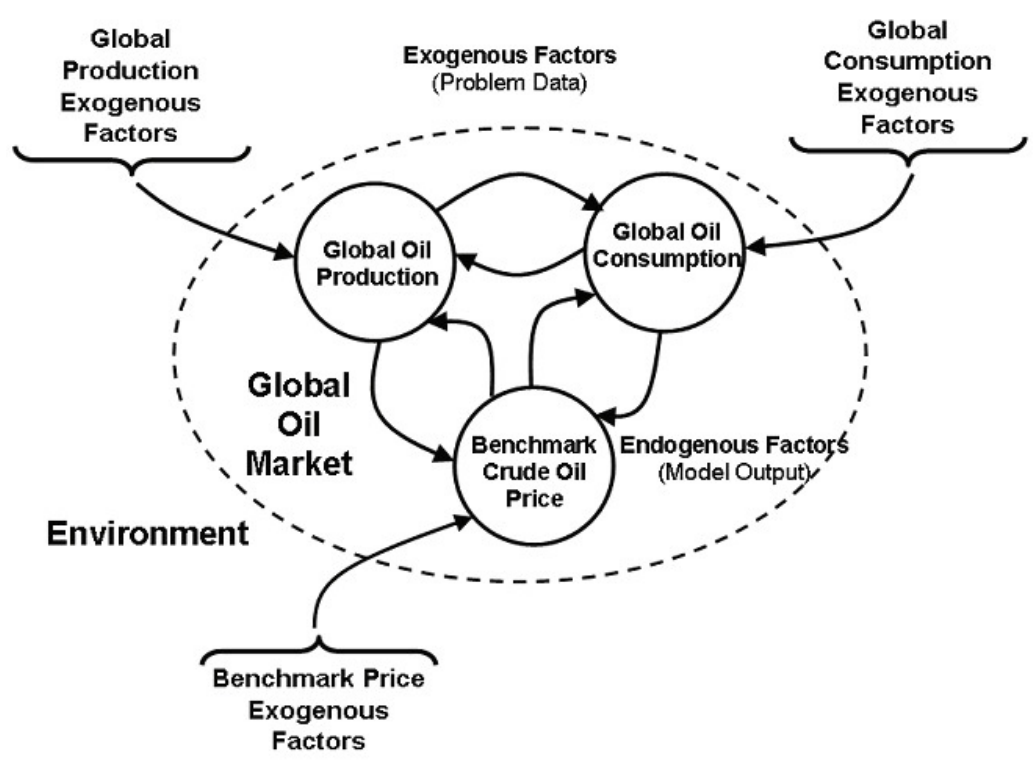

Figure 1 - Market interrelations according to the classical theory

Source: Developed by the authors. 
The model is dynamic because it considers all variables or factors as interrelated time series, taking into account cause-effect relationships and the time delays between the causes and the effects that they produce. The endogenous factors of the model are the market factors as indicated by the classical market theory approach: the price of crude oil, and its global production and consumption, besides a quantity proportional to the production/consumption or supply/demand imbalance; in turn, the exogenous factors are those that belong to the environment of the market and that affect the endogenous factors, causing them.

(a)

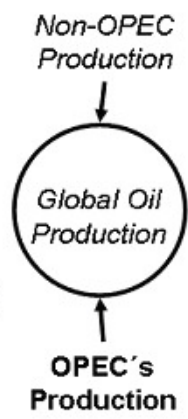

(d)

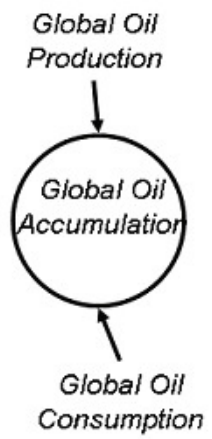

(b)

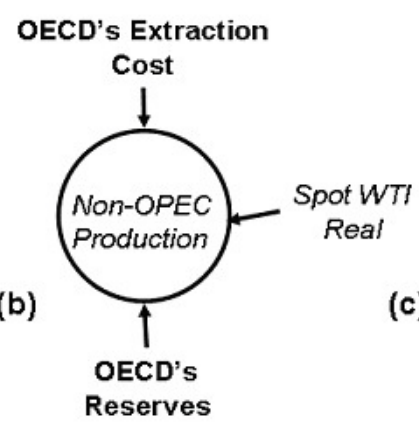

(c)

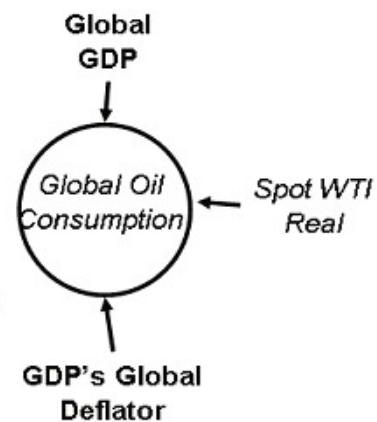

(e)

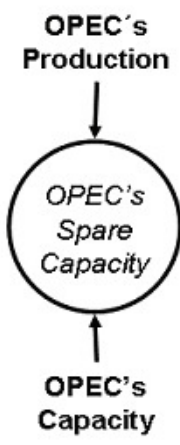

Deflator

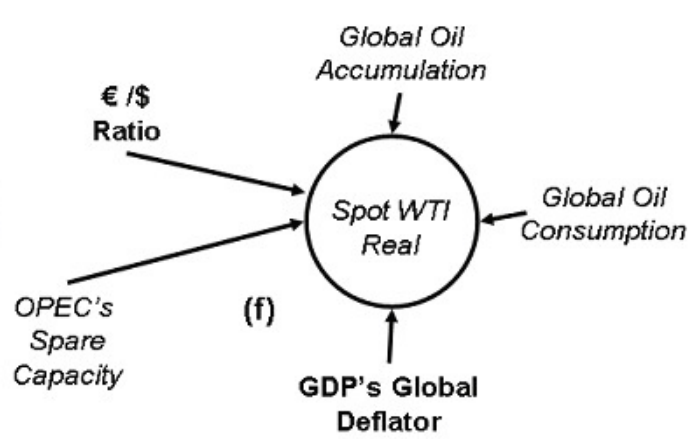

Figure 2 - Incident or casual factors for the endogenous variables of the model Source: Developed by the authors.

The assumption that the behavior of market endogenous factors is a function of the exogenous factors aligns the classical model of the market with the system (systemic) paradigm.

The purpose of the model is the simulation of the historical series of the global oil production and consumption, as well as those of the global oil accumulation and the price of WTI marker, based on the historical series of exogenous factors that affect the market.

For each of the endogenous factors of the model (in circles in (a) to (f) in Figure 2), Figure 2 shows its respective incident or causal factors; the incident factors that are endogenous in the model are indicated in italics, the rest being exogenous. Note that often a given variable affects another, and the other is in turn determined by the first, in a bidirectional feature of the model. The simulation of these bidirectional links in a cause-effect model necessarily requires the consideration of time delays that occur between the different processes in the phenomenon, since it is not possible that a factor could be the cause and effect of another simultaneously. 
Two agents are considered in global oil production, which is the sum of both: OPEC production, and the rest, to be called non-OPEC production. OPEC production is assumed to be a known fact, and therefore is an exogenous factor of the model; thus, OPEC's behavior is independent of other market factors. This scenario simulates an arbitrary behavior of OPEC in the allocation of production quotas. Non-OPEC production is then the endogenous factor of the model that corresponds to the supply side of the market, being the global consumption the endogenous factor that corresponds to its demand side. In turn, OPEC's spare capacity is the difference between OPEC's capacity and OPEC's production or output.

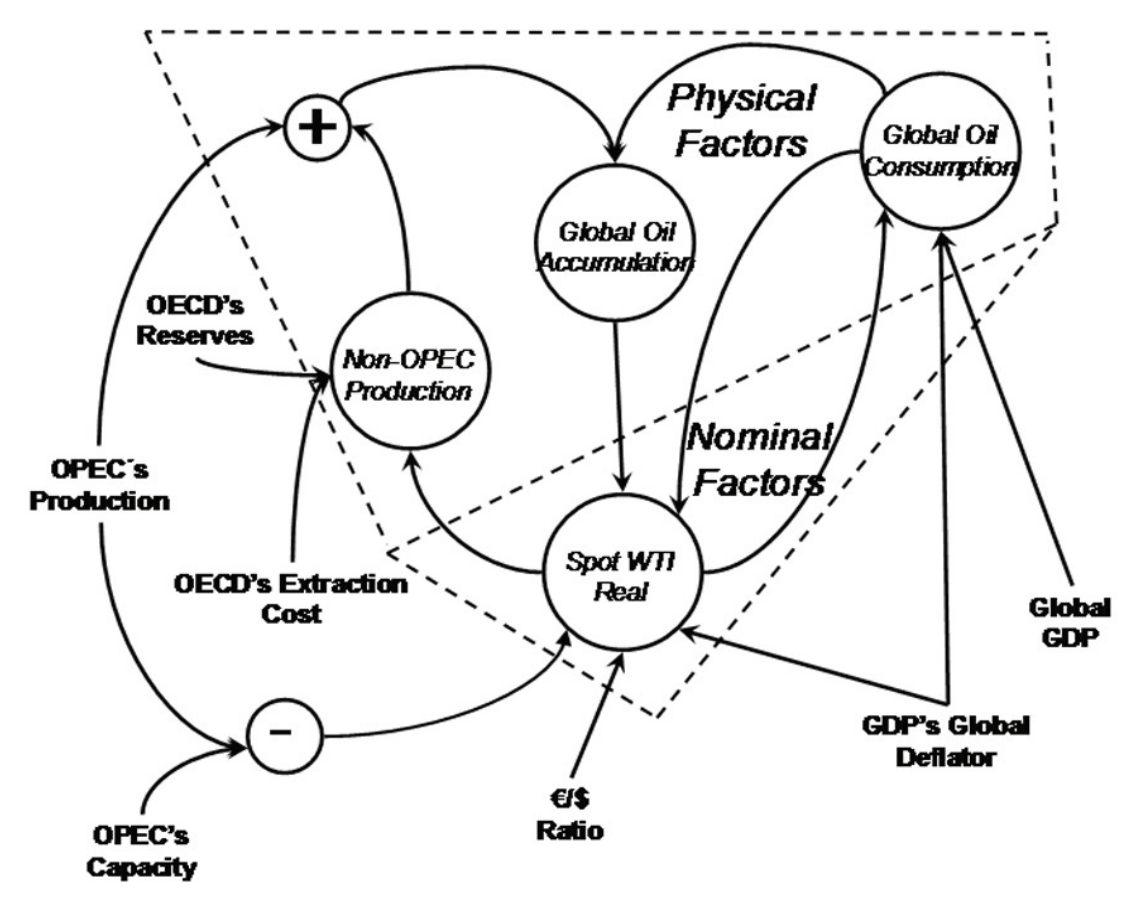

Figure 3 - Model of relationships for the GOM Source: Developed by the authors.

Solving the implicit interdependencies in Figure 2, and relocating the factors in the graph, a model of relationships for the GOM is shown in Figure 3. Feedback loops in the model suggest its non linear character. By their nature, the endogenous factors of the model can be classified into two broad categories: physical factors and nominal factors. Any physical factor has weight or material nature; any other that does not meet this condition is nominal in nature. Due to its weight, physical factors have inertia, so they are delayed effects of their causes; in turn, the nominal factors can be instantaneous effects of their causes, because they have neither material weight nor inertia. Then, two parts can be distinguished in the proposed model: a physical part of economic factors, shown in Figure 3; and a nominal part of financial or monetary factors, indicated in the same figure. Thus, the physical endogenous factors of the model are non-OPEC production, the global oil consumption and the global oil accumulation; and the nominal endogenous factor is the real price of benchmark crude WTI. 


\subsection{Simulation Procedures}

\subsubsection{Simulating the dynamics of nominal factors}

Nominal factors that are instantaneous effects of their causes can be calculated by a multiple regression of their explanatory factors. The multiple regression results in a co-integration equation in which time does not appear, meaning that the explained factor is simultaneous with respect to its explanatory factors. The diagram in Figure 4 illustrates the concept for the case of the real price of benchmark crude WTI.

Spot $W T$ Real $=[(4834.38)+$ $(-23.2628)^{\star}$ Global Oil Consumption + $(-2.0022)^{\star}$ Global Oil Accumulation + $(-59.342)^{\star} O P E C$ 's Spare Capacity + $(3.37273)^{\star} €$ I\$ Ratio+

$(0.164068)^{\star}$ Global Oil Consumption ${ }^{\star} O P E C$ 's Spare Capacity + $(-5.94032)^{\star}$ Global Oil Consumption ${ }^{\star} €$ I\$ Ratio + $(22.2935)^{\star}$ OPEC's Spare Capacity $€$ /\$ Ratio + $(0.208866)^{*}(\text { Global Oil Consumption })^{2}+$

$(0.000257058)^{*}(\text { Global Oil Accumulation })^{2}+$ $(2.41137)^{\star}(\text { OPEC's Spare Capacity })^{2}+$

$\left.(154.722)^{*}(€ / \$ \text { Ratio })^{2}\right]^{*}(130.85 /$ GDP's Global Deflator $)$

Figure 4 - Benchmark WTI real price simulation Source: Developed by the authors.

\subsubsection{Simulating the dynamics of physical factors}

Physical factors are delayed effects of their causes. By hypothesis of the model, such factors are calculated by accumulating their velocities or rates, as shown in Figure 5. The value of the factor at a given moment is the result of the accumulation (more precisely, integration) of the temporal change rate (rate of change) over the prior period that has elapsed since the beginning of the simulation, when it starts the accumulation process from a known initial value. 


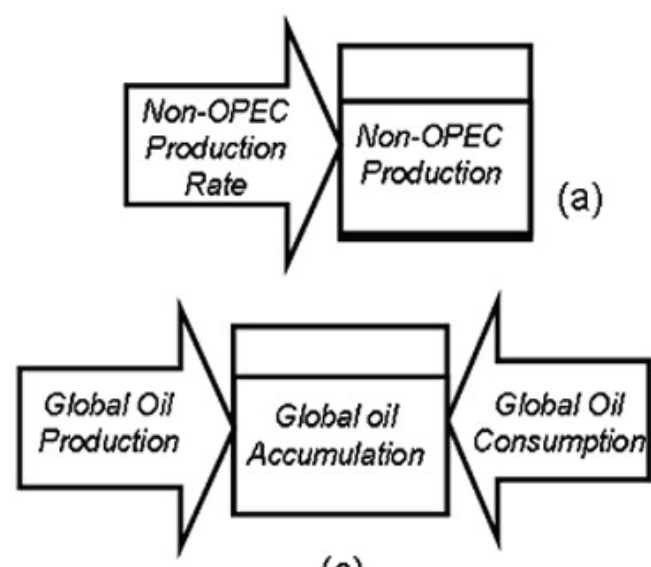

(c)

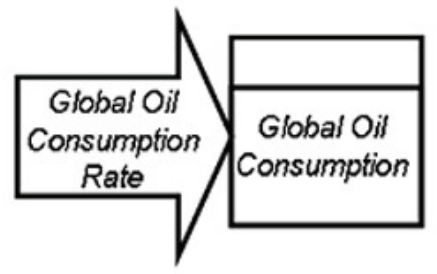

(b)

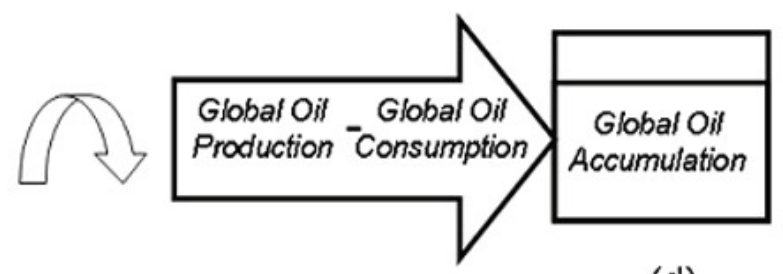

(d)

Figure 5 - Accumulation metaphor for the simulation of the physical factors of the GOM

Source: Developed by the authors.

This modeling methodology is particularly suited to factors that have physical sense and therefore require time to complete, such as oil production (a in Figure 5) and consumption (b in Figure 5), and the accumulation due to the existence of a difference between them (c and d in Figure 5). This accumulation metaphor, depicted in Figure 5, allows the appropriate consideration of delays due to the material inertia of the physical factors of the market.

\subsubsection{Dynamics of the rates in the simulation of oil production and consumption}

In the assumption that the velocities or rates can be identified with the decisions or desires to increase or decrease in certain amounts their respective factors, it can be stated that they respond instantly to their causal factors, i.e.the decision or desire to increase production varies instantaneously after changes in incidental factors, such as prices. Thus, these rates can be calculated from the co-integration of their explanatory factors. The diagram in Figure 6 depicts the concept for the rate of global oil consumption.

Global Oil Consumption Rate global cons rate $=(-0.00806045)+$ $(-0.00193368)^{*}$ real global gdp + $(0.00186404)^{*}$ Spot WTI Real + $(-5.2525 \mathrm{e}-005)^{*}$ real global gdp*Spot WTI Real + $(5.70967 \mathrm{e}-005)^{\star}(\text { rea/ g/oba/ gdp })^{2}+$ $(3.6783 \mathrm{e}-006)^{*}(\text { Spot } W T I \text { Real })^{2}$

Figure 6 - Simulation of the rate of global oil consumption Source: Developed by the authors. 
As for the rate of non OPEC production, it is proposed that it be a function of the rate of extraction cost and the replacement rate; the rate of extraction cost is calculated from its historical data, and the replacement rate is defined as the ratio between the change of non-OPEC reserves and the change of nonOPEC production. Thus, the simulation of non-OPEC production considers the problem of oil resource depletion.

Also, between the rates of cost of extraction, production and replacement, there are different time lags that are considered by the model; the magnitudes of those lags were established after adjusting the model for the period 1995-2008. Under these conditions, the diagram in Figure 7 shows the model for the rate of non-OPEC production.

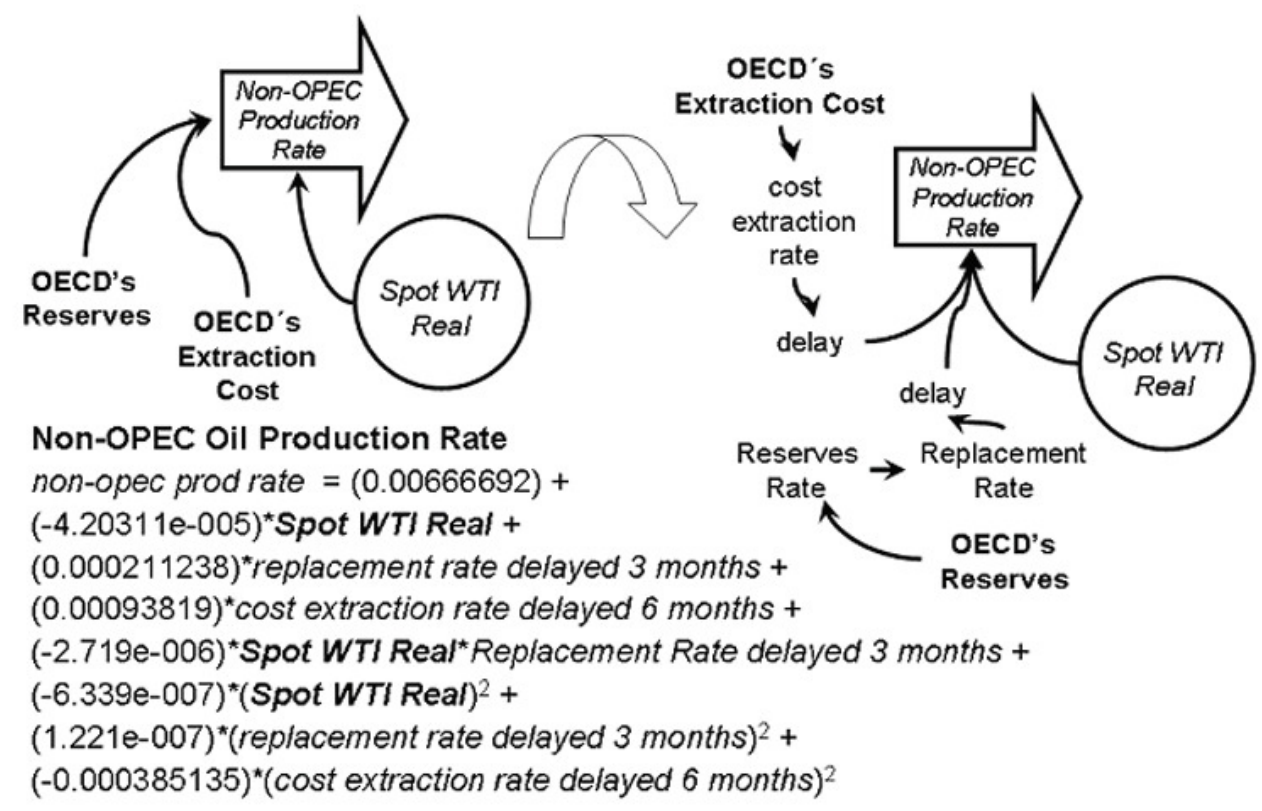

Figure 7 - Simulation of the rate of non-OPEC production

Source: Developed by the authors. 


\subsection{Measurements and Historical Data: Parameters of the Model}

Implementation of the model requires the evaluation of all of its parameters, corresponding to the coefficients of the co-integration equations that are necessary to simulate the price of the WTI marker as well as the rates of global consumption and non OPEC production, in accordance with the procedures and metaphors proposed in the previous sections and illustrated in Figure 5. To this end, the historical series of average annual values between 1995 and 2008 were collected, for all the factors that are included in the model, both exogenous and endogenous. Model data was retrieved from widely used and publicly available sources. The factors included in the model are Real WTI Spot Price $^{1}$, Global Oil Consumption ${ }^{2}$, Global GDP Deflator ${ }^{3}$, Global Oil Production ${ }^{4}$, OPEC's Spare Capacity ${ }^{5}$, Global Oil Stocks ${ }^{6}$, OECD's Reserves ${ }^{7}$, Non OPEC Production ${ }^{8}$, OECD's Extraction Cost $^{9}$, Nominal Global GDP ${ }^{10}$ and $\$ / €^{11}$.

The coefficients of the co-integration equations with interaction terms for SpotWTI (Figure 4), the rate of global consumption (Figure 6) and the rate of non-OPEC production (Figure 7) were obtained from the multiple regression of the historical series of the factors of the model, by means of the regress function in Matlab ${ }^{\circledR}$ version R2007a. In each case, the decision of what to include as interaction terms in the equation was the result of a compromise between a good simulation of the factor and a good behavior of the equation within the context of the dynamic model, since the more interaction terms are included, the better the simulation (or fitting) of the factor when considered separately, but in some cases, when performing within the whole dynamic feedback model, the behavior of the simulator tends to be unstable.

\subsection{Overview of the System Dynamics Model of the GOM}

Figure 8 shows the integration of the dynamics of physical and nominal factors and their rates into the relations model depicted in Figure 3.

1 In \$/b, from http://www.bp.com/statisticalreview, BP Statistical Review 2008.

2 In b/day, from http://tonto.eia.doe.gov, STEO Table Browser, table $3 a$.

3 Year $2000=100$, from World Bank, World Development Indicators, ERS Estimates, 12/17/07 update.

4 In b/day, from http://tonto.eia.doe.gov, STEO Table Browser, table 3a.

5 In b/day, from Petroleum Intelligence Weekly, September 3, 2007.

6 In MMb, from http://tonto.eia.doe.gov/merquery/mer_data.asp?table=T11.03.

7 In MMMb, from BP Statistical Review of World Energy, June 2008.

8 In b/day, from http://tonto.eia.doe.gov, STEO Table Browser, table 3a.

9 In $\$ / b$, from http://www.eia.doe.gov/emeu/perfpro/index.html, EIA, Perf. Profiles of Major Energy Producers, 2007.

10 In MMMM\$, from http://www.nationmaster.com/graph/eco_gdp-economy-gdp.

11 In $\$ / €$, from http://research.stlouisfed.org/fred2/series/EXUSEU.

LÓPEZ-DOMÍNGUEZ, M. F.; LEVY-CARCIENTE, S.; CONTRERAS, J.; PAIVA-MATA, P.C. Behavior of the global... 


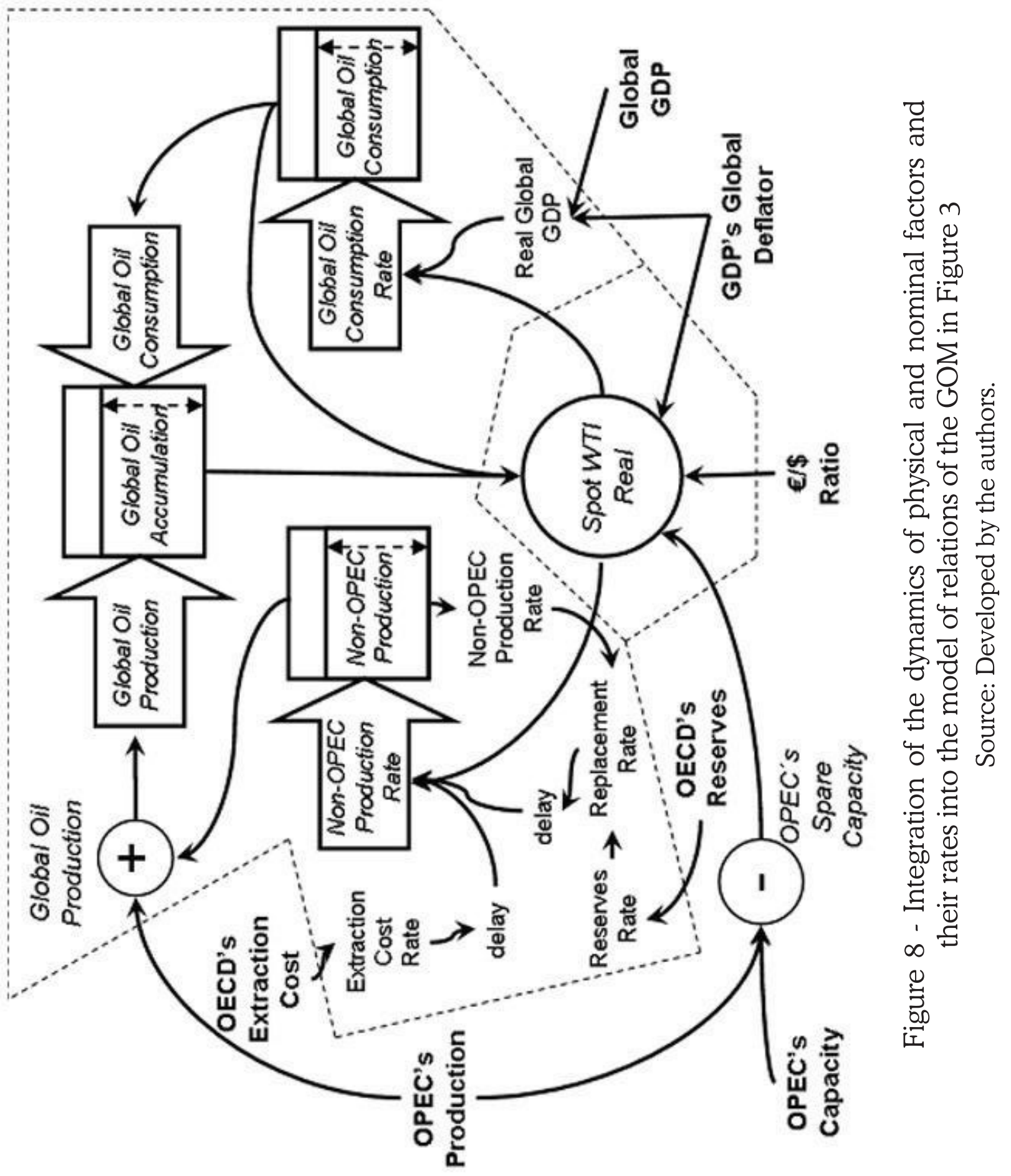


The structure and characteristics of the proposed model make it directly implementable in the environment of a piece of software specifically designed for simulations based on system dynamics: VENSIM ${ }^{\circledR}$, which is widely available and extensively used. Figure 9 shows that the VENSIM ${ }^{\circledR}$ model for the dynamic simulation of the GOM can be obtained directly from the model in Figure 8.

In summary, a feedback dynamic model of the GOM has been proposed to simulate complex nonlinear interactions among the factors that affect it. Two parts can be distinguished in the model: one that addresses the economic or physical part of the global oil market (supply/production, demand/consumption, and the imbalance between both) and the other, of nominal nature, focused on the evaluation of the price. The nominal and physical parts of the model are interrelated according to a general feedback market model with closed loops. This type of closed loop interactions between the variables, which is inherent to a model of dynamic system simulation, can hardly be replicated in conventional econometric models. 


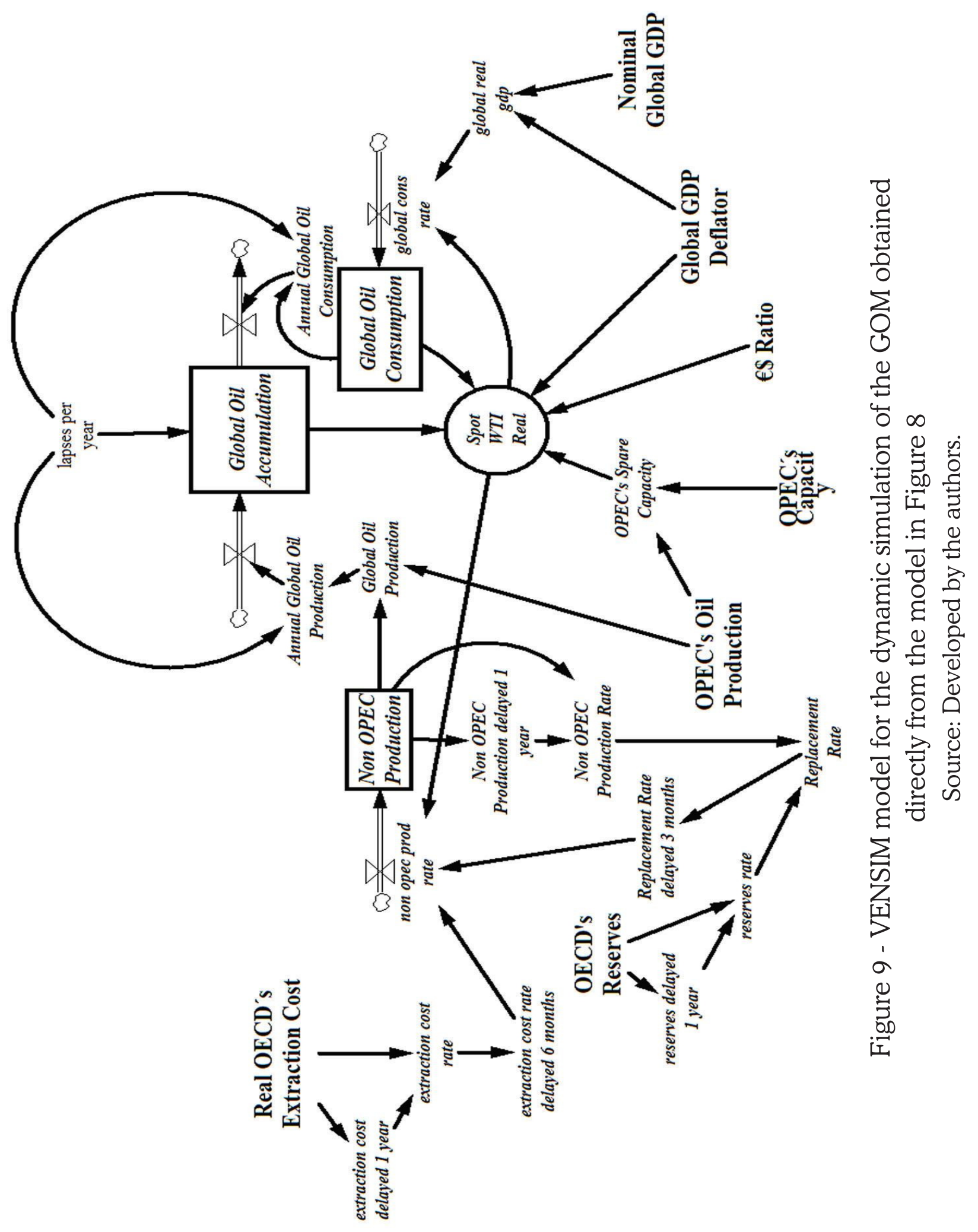




\section{Results}

\subsection{Model Validation}

From the data of the variables involved for the period 1995-2008, multiple regressions were determined (Figures 4, 6 and 7), and the model was run using Vensim ${ }^{\circledR}$ version 5.3. The goal was to obtain simulations for the endogenous factor of the model during a time lapse in which their true behavior was known, 19952008. Then, by comparison between the simulations and the truth, the performance of the dynamic model as a GOM simulator could be assessed.

The Appendix shows the graphs describing the real behavior and its respective simulation for each of the endogenous factors of the model. Results show a satisfactory performance, producing simulated time series for the main endogenous factors: crude oil benchmark price, production, consumption and global accumulation. Simulations reproduce properly the trends shown by the true historical series, with maximum absolute errors in the simulations of production, demand and accumulation of $1.47 \%, 0.69 \%$ and $4.87 \%$, respectively, when compared to the true series. The simulation of the benchmark WTI price was performed within an error band of $(-9.26,+2.55)$ dollars per barrel before 2000, narrowing this band to $(-5.39,+2.21)$ when simulating between 2000 and 2008 . These errors point to reasonably acceptable levels of accuracy in the simulations of the endogenous factors of the model.

Some special attention deserves the simulation of the replacement rate, which shows a significant discrepancy in 2006. The replacement rate is defined as the ratio between the change in non-OPEC reserves and the change in non-OPEC production. Therefore:

(A) The replacement rate shows a positive sign if both the change in reserves and production variation refer to in the same direction (both increase or decrease); otherwise it will be negative.

(B) The replacement rate magnitude will be significant if the production variation is small or if the change in reserves is substantial. In the limit, the replacement rate is infinite if in a given period non-OPEC production remains constant, or if in a given period reserves grow infinitely. The latter case does not occur in practice.

The 2005-2008 period was characterized by small positive changes in nonOPEC production about an almost constant average, which is reflected in high values of the historical replacement rate for that specific period. However, the simulation of the non-OPEC production for that same period is slightly decreasing (see the non-OPEC production simulation vs. truth in the Appendix); hence, in magnitude, although the replacement rate coincides with the historical data, it does not in sign. 


\subsection{Sensitivity Study}

In order to evaluate aspects of the model such as stability, performance to errors, relevance of exogenous factors and any conclusions about the dynamic behavior of the oil market, a sensitivity study was performed. The study was based in the application of uniform random noise around the true or historical values of exogenous factors, one at a time, to observe in each case the response of all the endogenous factors, in magnitude and distribution. Thus, in each experiment, the impact of one input over all of the outputs is assessed; for this, the 200 responses of the output variable due to 200 changes in the input variable are evaluated. The changes in the input have a default maximum excursion and uniform distribution around its historical value. Changes in the output are observed, in excursion and distribution around the expected response to the historical value of the input.

Table 1 - Macroeconomic Scenario

\begin{tabular}{l|l}
\hline Year & \multicolumn{1}{c}{ Macroeconomic scenario } \\
\hline 1995 & $\begin{array}{l}\text { Post Iran I war stable global economy (1993-1999) } \\
\text { Start of recovery from the 1999 oil prices crisis and } \\
\text { beginning of the 2001 recession episode } \\
2000\end{array}$ \\
2007 & $\begin{array}{l}\text { End of several years of sustained growth (2004- } \\
\text { 2007) and symptoms of imminent recession. }\end{array}$ \\
\hline
\end{tabular}

Source: Developed by the authors.

For the proper evaluation of the impact of exogenous changes on individual endogenous factors in a relatively comparable basis, it is proposed that a sensitivity index be calculated for each experiment in which the impact of changes of the exogenous $\mathrm{X}$ factor in the response of endogenous $\mathrm{Y}$ factor is to be assessed. Such index is given by the quotient of two quantities A and B, where $A$ is the relationship between the maximum excursion of the response of the endogenous factor $\mathrm{Y}$ due to changes in the exogenous factor $\mathrm{X}$, and the historical maximum excursion of the endogenous factor $Y$; and $B$ the relationship between the maximum excursion of the perturbation noise in exogenous factor $\mathrm{X}$, and its historical maximum excursion. Thus, the sensitivity index may admit the meaning of the gain of the model in the response of the output variable $Y$ due to variations in the input variable $\mathrm{X}$.

The aim of calculating sensitivity indexes is to obtain data showing the sensitivity and proportionality of the response of each endogenous factor to variations in each of the exogenous factors; thus, irrelevant factors may be ruled out, and general trends may be detected. The proposed methodology is applied to three points in the known history, 1995, 2000 and 2007, in order to detect temporal trends in the relations between the factors (if any), and relate them 
to global macroeconomic scenarios prevailing in the selected points. Those macroeconomic scenarios are briefly described in Table 1.

Inputs are perturbed randomly, one at a time, in 1995, 2000 and 2007, and the response of each endogenous factor in 1996, 2001 and 2008 is observed (respectively), in amplitude and frequency distribution, and an index of sensitivity is calculated in each experiment. Thus, a local (in a time frame basis) sensitivity study is performed. For almost all exogenous variables, simulations are run for 200 disturbances within a band of width equal to $20 \%$ of the historical value of the disturbed variable in 1995, 2000 and 2007; then, the disturbances take place in the form of uniform random noise around the historical value (i.e. $\pm 10 \%$ ). Some exceptions took place: for RESERVES in 1995, the width of the band is $5 \%( \pm 2.5 \%)$, and for DEFLATOR, OPEC's CAPACITY and $\$ / €$ in 2007 , the width is $17.5 \%( \pm 8.75 \%)$. The differences in the excursions of the perturbations of the inputs are due because of the various sensitivity levels that differ, in some cases, in an order of magnitude, or two.

For a better understanding of the meaning of sensitivity indexes, a scale of interpretation is proposed, by defining a sensitivity level based on a qualitative interpretation of the range of the index of sensitivity. This definition is arbitrary, but it aptly describes the effect and meaning of the sensitivities in the context of the model. Table 2 defines the aforementioned scale.

Table 2 - Scale of interpretation for the results of the sensitivity study

\begin{tabular}{c|c|c}
\hline Sensitivity index range & Sensitivity level & $\begin{array}{c}\text { Qualitative description of } \\
\text { the level }\end{array}$ \\
\hline$<0.1$ & 0 & Insensitive \\
$(0.1,<0.3)$ & 1 & Fairly Sensitive \\
$(3.0,<1)$ & 2 & Sensitive \\
$(1,3.5)$ & 3 & Very Sensitive \\
$>3.5$ & 4 & Extremely Sensitive \\
\hline
\end{tabular}

Source: Developed by the authors.

Resulting sensitivity indexes are in Figure 10, which summarizes the results for the years in which local sensitivity was studied: 1995-96, 2000-01 and 200708. Figure 10 also contains additional information, related to the qualitative interpretation of the magnitudes of the sensitivity indexes, as well as the behaviors (in proportionality) of the responses. Figure 11 explains the meaning of the symbols in Figure 10, and Figure 12 describes the contents therein. Figure 13 shows, as a typical example, the result obtained for the evaluation of real SpotWTI sensitivity to changes in GDP in 1995, showing the calculation of its corresponding sensitivity index. It also shows the frequency distribution of the response, which is directly proportional (i.e. when the input grows, the output grows and when the input decreases, the output decreases; the response of some other factors is 
defined as inversely proportional, i.e. when the input grows, the output decreases, and when the input decreases the output grows). Notice that the distribution has a double bell shape centered on the value of the response without noise. The double bell distribution appears in most of the responses to perturbations of individual inputs, and suggests the existence of two Gaussian processes that result in responses grouped around two means, one for the noise above the historical value of the endogenous factor, and the other for the noise below it. When all inputs are disturbed at the same time, all the responses tend to simple Gaussian distributions around their responses without noise.

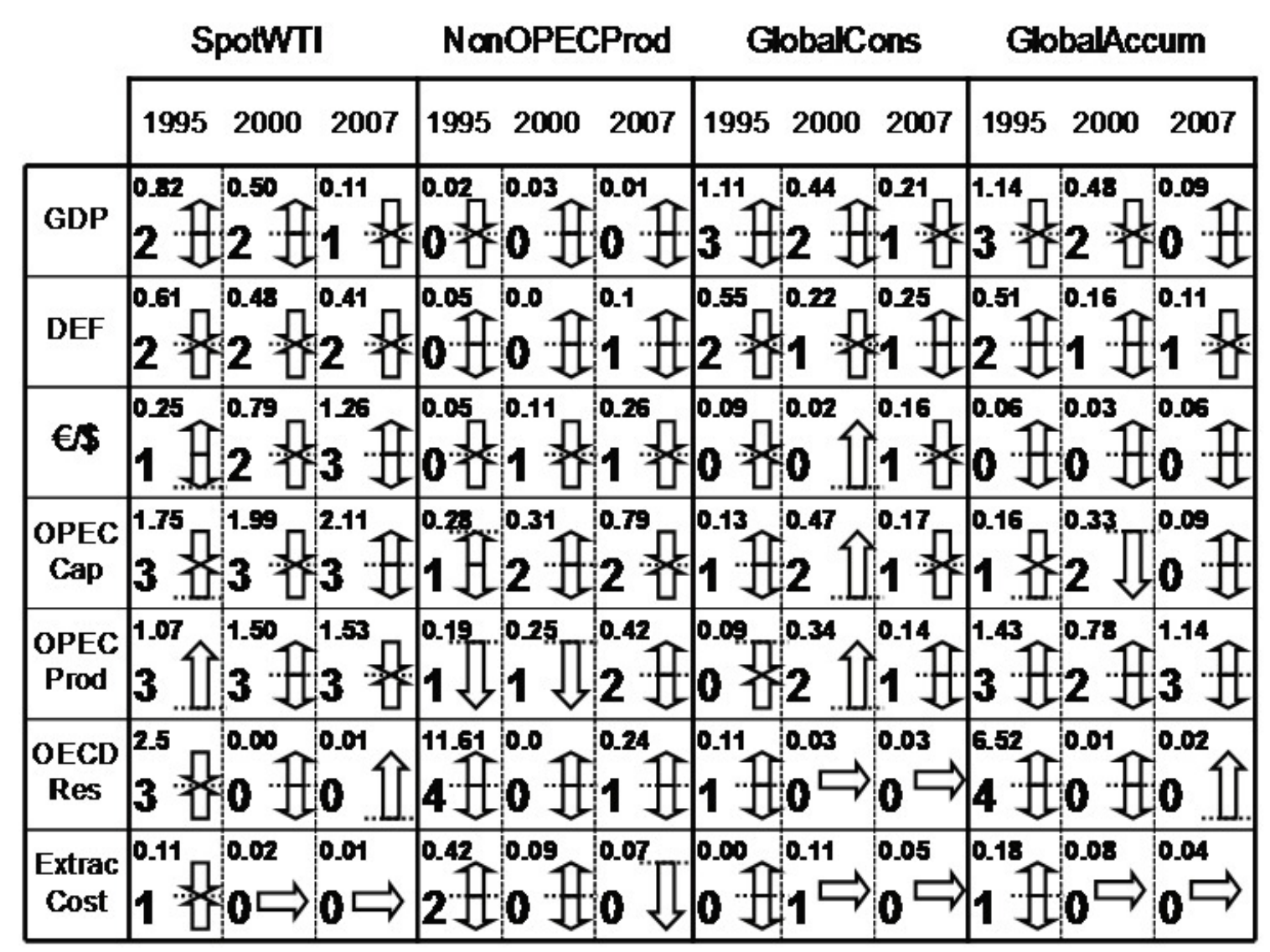

Figure 10 - Results of the sensitivity study

Source: Developed by the authors.

Figure 14 shows in bar graphs, for comparison purposes, the variation of the sensitivity index for each of the endogenous factors of the model due to all the exogenous factors in the years 1995, 2000 and 2007, and Figure 15 shows the same information but without data about the indexes for non-OPEC production and global oil accumulation due to variations in reserves, to highlight the behaviors on the other sensitivities otherwise shadowed by the impact of reserves in 1995 for these two factors. Figure 16 shows the same information as Figure 14, but taking in each case the sensitivity index in 1995 as the reference for the relative sensitivities in 2000 and 2007. Thus Figure 16 gives a clearer picture of how sensitivities change or evolve over the period. The analysis of the contents of the figures can provide useful information about the dynamic behavior of the global 
oil market in the historical period considered, 1995-2008. Figure 16 does not show data about relative sensitivities of global consumption due to changes in extraction costs, because the corresponding sensitivity index is 0 (or negligible) in 1995, producing relative sensitivities of infinite magnitude for the other years.

- Distributions of the perturbed (noisy) Inputs:

- Uniform Random Distribution around Historic Value -

- Distributions and Behaviors of the Ouputs (Responses):

- Directly Proportional around expected value (*) _-_._.

- Inversely Proportional around expected value

tr

- Directly Proportional Under (Over) expected value -

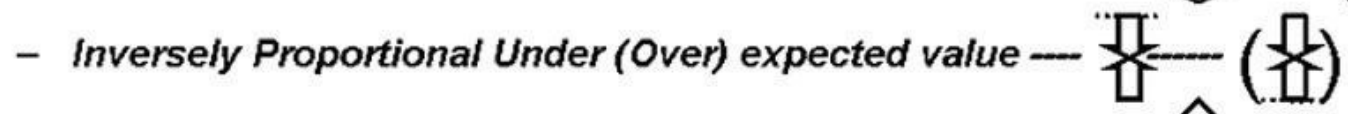

- Always Over expected value -

- Always Under expected value _-_

- Constant or Almost Constant Response - $\Rightarrow$

$\left.{ }^{*}\right)$ The expected value of an output is the response due to the historic value (without noise) of the input

Figure 11 - Meaning of the symbols in Figure 10

Source: Developed by the authors.

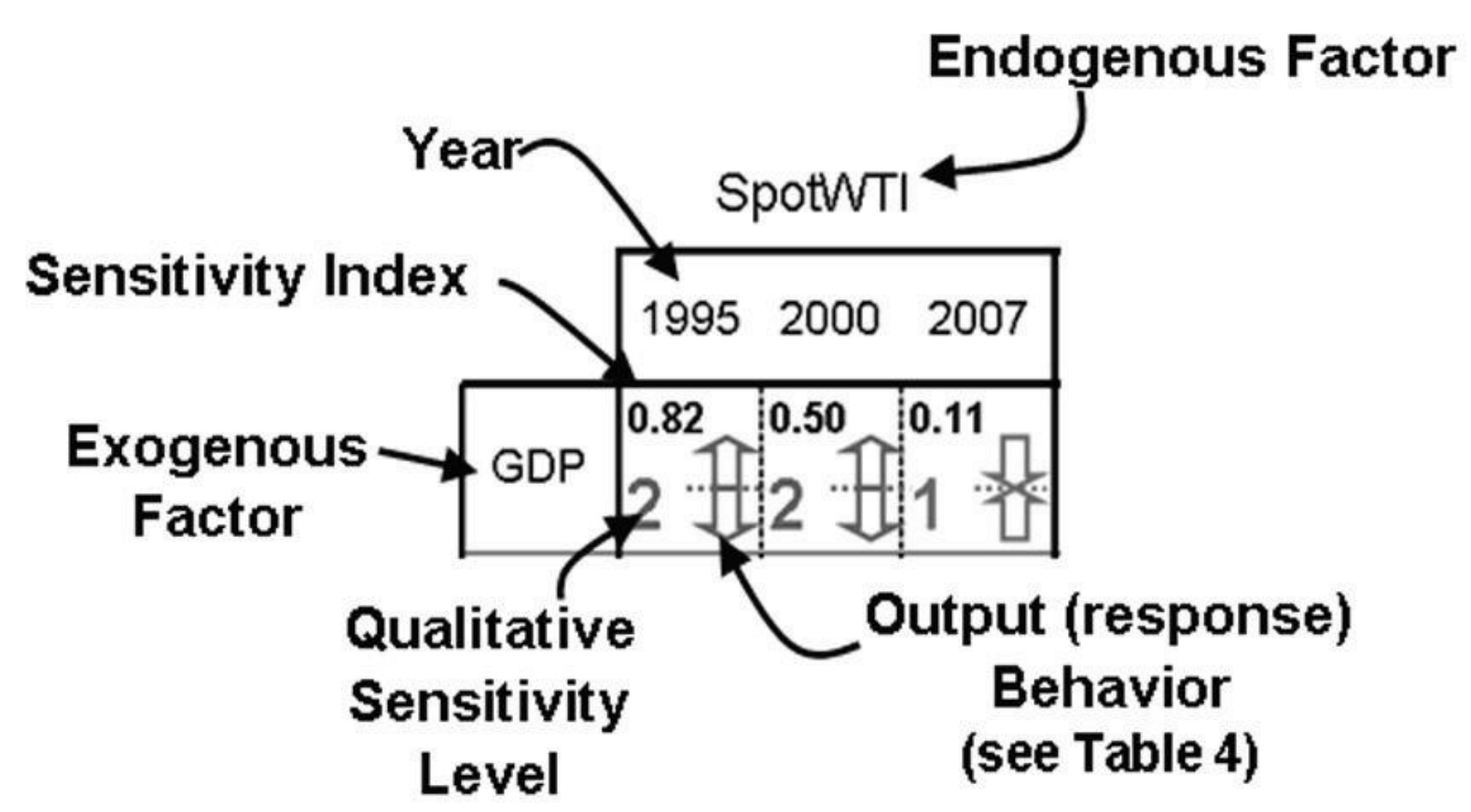

Figure 12 - Contents of Figure 10

Source: Developed by the authors.

LÓPEZ-DOMÍNGUEZ,M. F.; LEVY-CARCIENTE, S.; CONTRERAS, J.; PAIVA-MATA, P.C. Behavior of the global... 

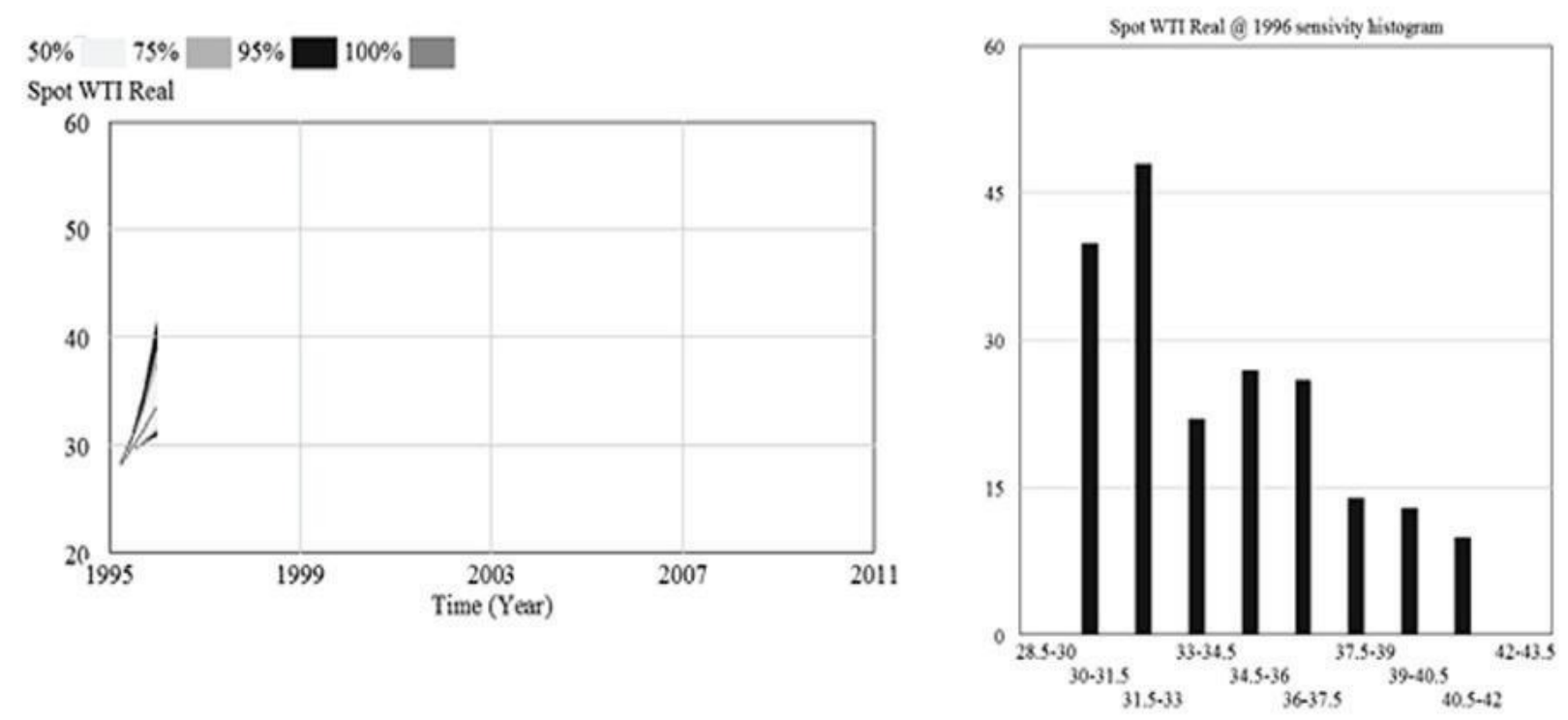

Stimulus $\rightarrow$ Max. GDP variation excursion: $20.57 \%$ of its maximum historic variation Response $\rightarrow$ Max. SpotWTI variation excursion: $16.88 \%$ of its maximum historic variation Then: $16.88 \%$ is $82 \%(0.82)$ of $20.57 \% \rightarrow$ Sensitivity Index $=0.82$

Figure 13 - As a typical example, the result (sensitivity histogram) obtained for the evaluation of real SpotWTI sensitivity to changes in GDP is shown; text in the figure describes the calculation of the sensitivity index.

Source: Developed by the authors.

\section{Discussion: Dynamic Behavior of the GOM, 1995-2008}

The analysis of the contents in Figures 14, 15 and 16 can provide useful information about the dynamic behavior of the GOM in the historical period considered in the study of sensitivity. Here, only some of the aspects that can be drawn from the results are discussed.

Most exogenous variables in the model are structural (of economic nature), such as production capacity, reserves and associated costs, and deflated economic growth, so the model is considered to be structural in type; but, for the sake of completeness, it also includes an exogenous financial or monetary factor (the $\$ / €$ ratio), which is necessary to consider the fundamental fact that while the oil market operates in U.S. dollars, its agents also operate in other currencies, requiring conversion and linking processes in which other factors of non-structural nature have decisive weight, such as currency speculation, financial considerations, speculation in securities and commodities markets, stocks trade, etc. These other factors also impact the global oil market, and the dynamic model somehow tries to include them by considering the $\$ / €$ ratio. 


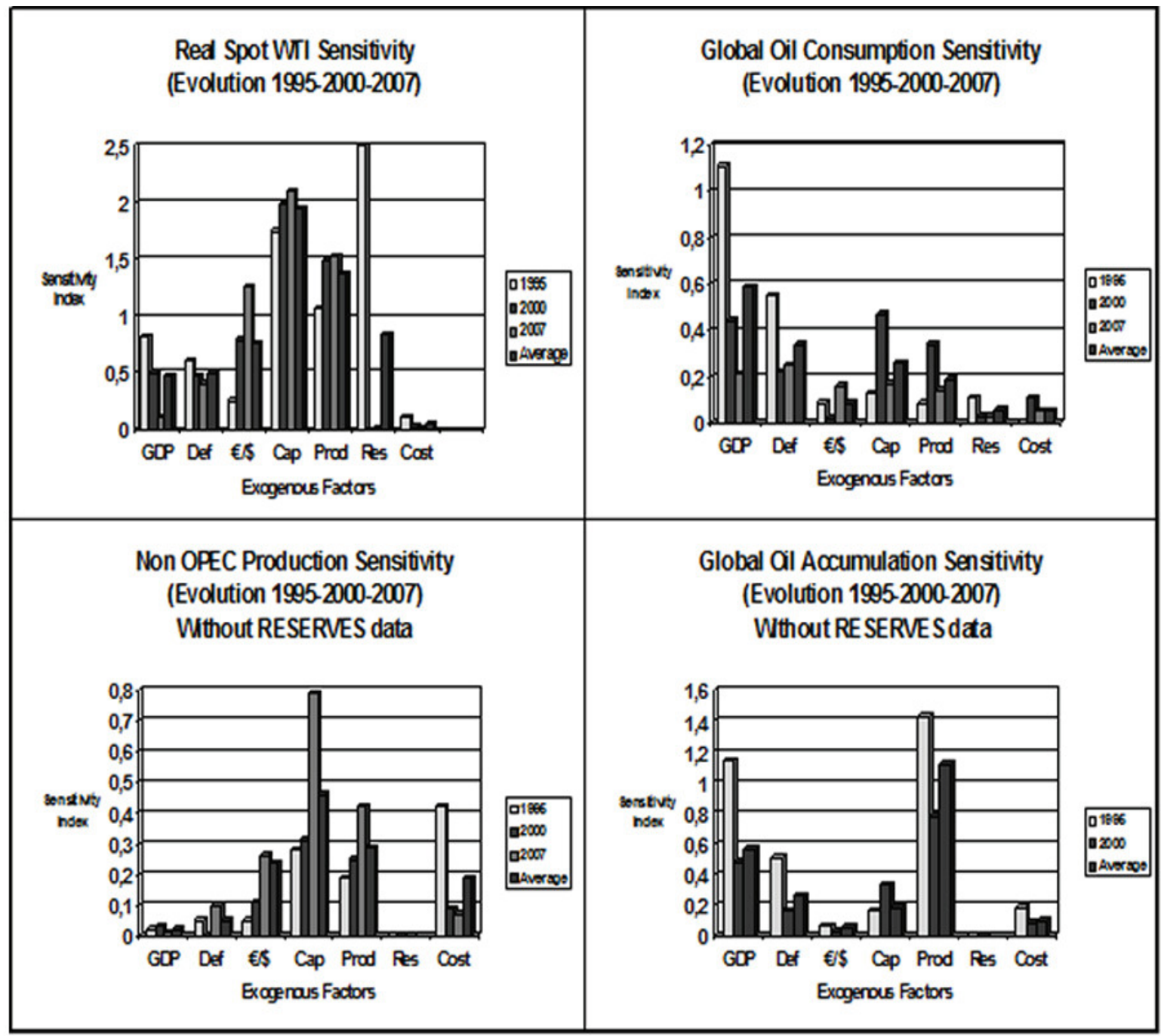

Figure 14 - Variation of the sensitivity index for each of the endogenous factors of the model due to all the exogenous factors in the years 1995, 2000 and 2007 Source: Developed by the authors.

The set of exogenous factors of the GOM structural dynamic model is designed to take into account the main economic agents that affect the market, such as the global macroeconomic environment, as well as the OPEC, and the non-OPEC producers mainly grouped in the OECD. The exogenous structural macroeconomic variables are the GDP and its deflator; the structural OPEC factors are its production capacity and its net production; and the structural OECD factors are its proven oil reserves and extraction cost per barrel. These structural factors, together with the financial or monetary factor $\$ / €$, constitute the set of exogenous factors of the dynamic model of the GOM. 


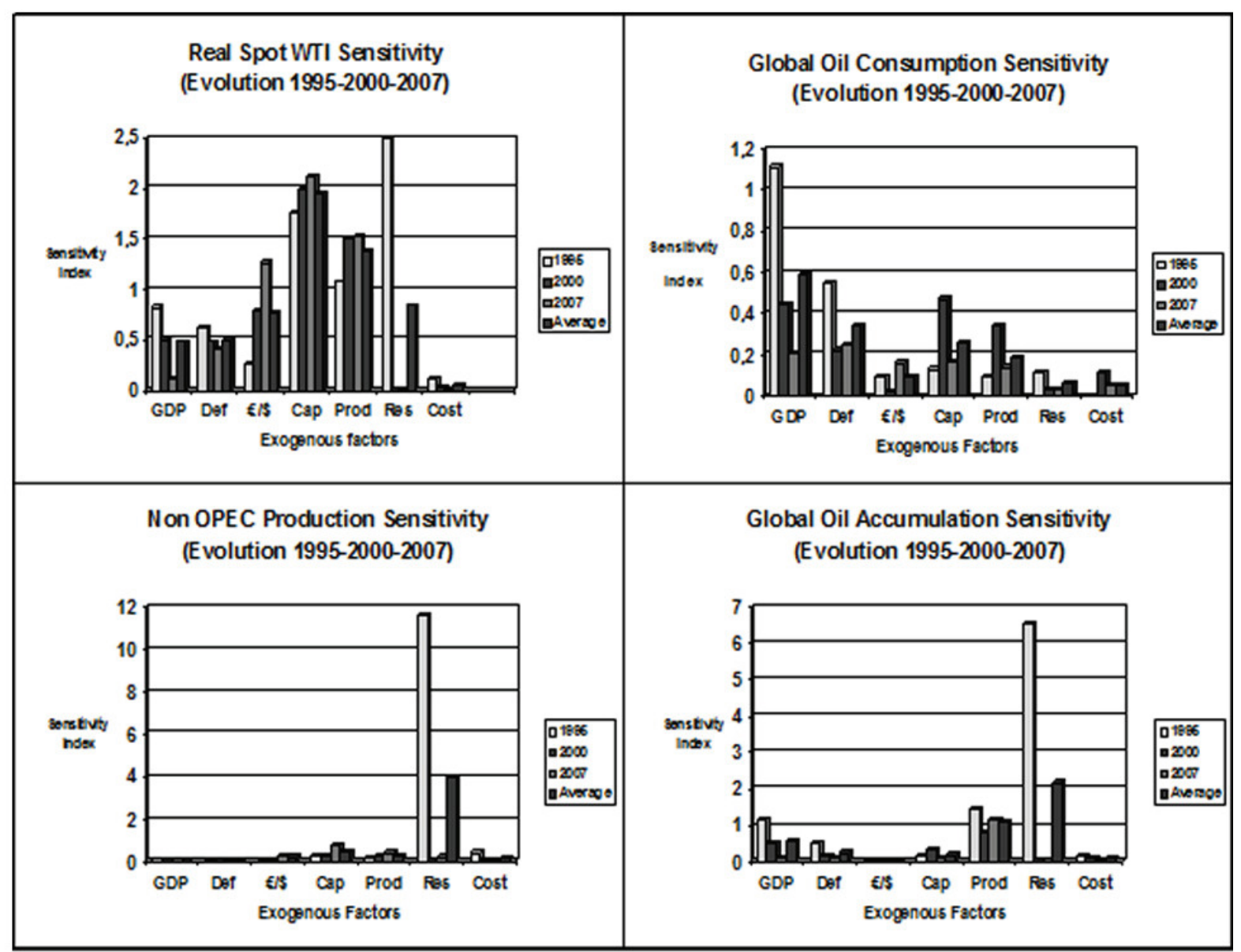

Figure 15 - Same as Figure 14 but without data about the indexes for non OPEC production and global oil accumulation due to variations in RESERVES Source: Developed by the authors.

The observation from Figures 14, 15 and 16 allows a qualitative description of the characteristics and dynamics of the different sensitivities of the model, which could lead to interesting conclusions about how the global oil market behaves. Figures 14 and 15 make it possible the description of the behavior in the sense of the degree of impact of exogenous factors on each endogenous factor, while Figure 16 provides information about how these impacts change throughout the history. Figure 17 summarizes in qualitative terms the test results in Figures 14 and 15. 


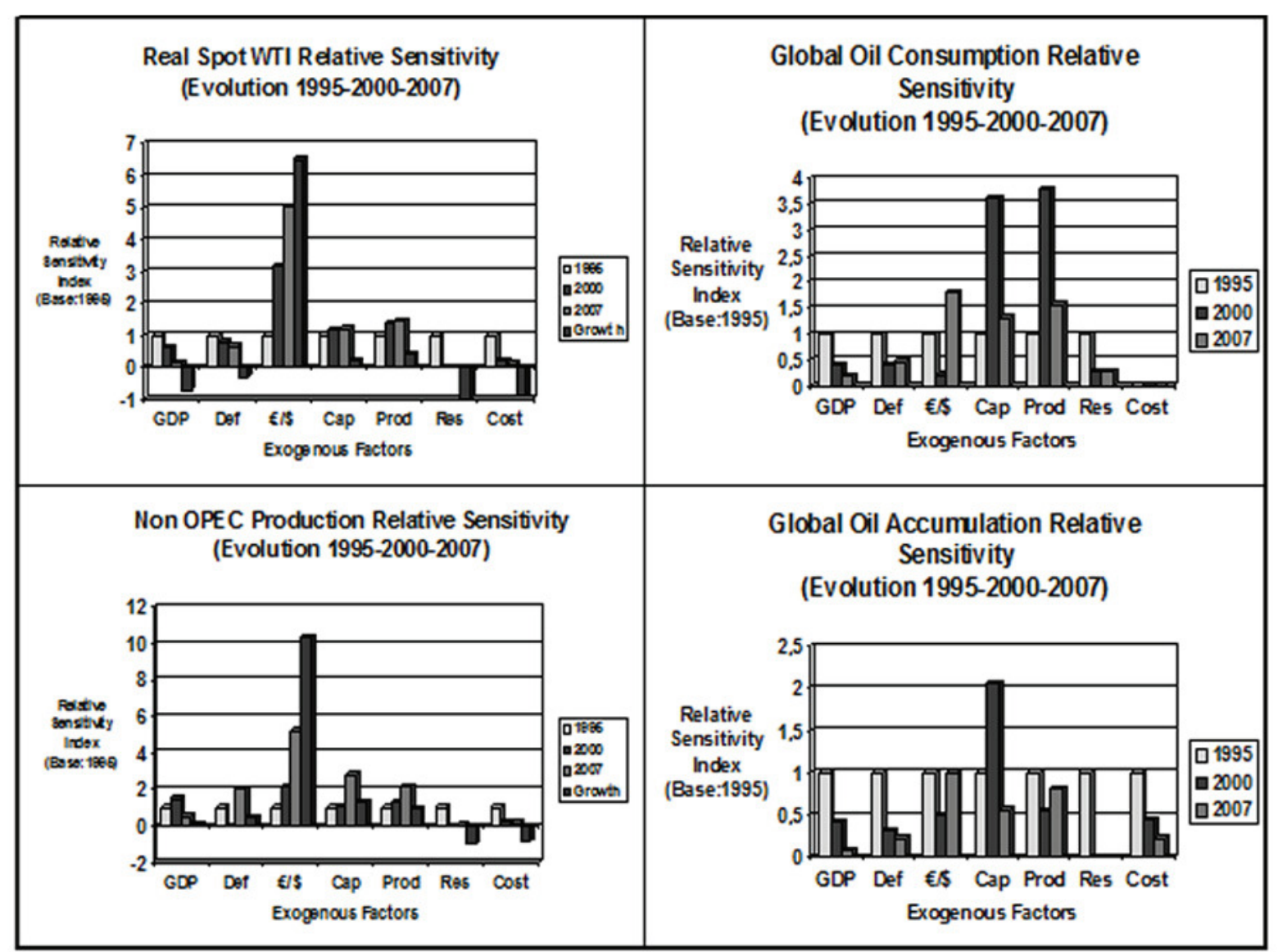

Figure 16 - Same as Figure 14 but taking in each case the sensitivity index in 1995 as the reference for the relative sensitivities in 2000 and 2007

Source: Developed by the authors.

Some interesting observations emerge from the examination of Figure 17. Factors related to OPEC have a strong influence (or impact) in the price of benchmark crude WTI, while, in comparison, macroeconomic and monetary factors affect moderately; similar behavior occurs with the production of non-OPEC countries, with the difference that the impact of macroeconomic exogenous factors is much smaller. For global oil consumption, the impact of macroeconomic factors is strong, while the OPEC factors affect moderately, and all other factors have a low incidence. Finally, the global accumulation is strongly affected by the global gross product, OPEC's production and reserves of non-OPEC countries (OECD), compared with the effect of other factors; the accumulation of oil is weakly affected by the monetary factor $\$ / €$ and the costs of extraction.

In turn, as it relates to the growth trends of the relative sensitivities of oil prices and non-OPEC countries production throughout the 1995-2008 lapse, Figure 18 qualitatively summarizes the test results in Figure 16; those are factors in which well-defined trends of sensitivity growth or decrease can be observed for all exogenous factors, a feature not so clearly satisfied in the cases of global consumption and global accumulation. 


\begin{tabular}{|c|c|c|c|c|c|c|c|}
\hline \multirow[b]{3}{*}{$\begin{array}{c}\text { Endogenous } \\
\text { Factors }\end{array}$} & \multicolumn{6}{|c|}{ Exogenous Structural Factors } & \multirow{3}{*}{$\begin{array}{c}\begin{array}{c}\text { Monetary } \\
\text { Exogenous } \\
\text { F actors }\end{array} \\
€ / \$\end{array}$} \\
\hline & \multicolumn{2}{|c|}{ Macroeconomic } & \multicolumn{2}{|c|}{ OPEC'S } & \multicolumn{2}{|c|}{ OECD'S } & \\
\hline & GDP & DEF & CAP & PROD & RES & COST & \\
\hline SpotwTI & MODERATE & MODERATE & HIGH & HIGH & MODERATE & Low & MODERATE \\
\hline NonOPECProd & Low & Low & HIGH & HIGH & HIGH & MODERATE & MODERATE \\
\hline GlobalCons & HIGH & HIGH & MODERATE & MODERATE & Low & Low & Low \\
\hline GlobalAccum & HIGH & MODERATE & MOOERATE & HIGH & HIGH & Low & Low \\
\hline
\end{tabular}

Figure 17 - Qualitative summary of test results in Figures 14 and 15

Source: Developed by the authors.

Note: There is an impact qualitative descriptor (low, moderate, high) for each pair (endogenous factor, exogenous factor), which describes the general level of impact of the exogenous factor (input) upon the endogenous factor (output) throughout the history (1995-2008).

Figure 18 indicates that over the period 1995-2008 the sensitivity of the WTI benchmark crude prices to changes in exogenous structural factors has decreased or increased slightly, while the sensitivity to exogenous monetary or financial factor $(\$ / €)$ grew strongly; in this way, the dynamic model suggests that the phenomenon of soaring oil prices until 2008 was due to speculative and financial factors (the ratio $\$ / €$ is strongly related to factors such as speculation in stocks and shares, world stock markets, currency speculation, commodity prices, etc..), seeming to clearly reject for this phenomenon the impact of macroeconomic structural factors (notice that the decrease in sensitivity of oil price to GDP is strong), as well as the impact of other structural factors of obvious influence on the oil market, such as the level of nonOPEC reserves and the oil extraction costs incurred by those countries.

OPEC factors retained their level of impact over the whole period in a relatively constant fashion, which seems to imply that these factors can not be regarded as the determinants of the rise of prices in 2007-2008.

Figure 16 suggests an interesting correlation in the dynamic behavior of the sensitivities between the global oil consumption and accumulation. Notice that in both cases the relative sensitivities do not show a general and regular pattern of increase or decrease over the period 1995-2008, as price and non-OPEC production do; instead, the structural OPEC factors, as well as the financial factor $\$ / €$, have a particular behavior in 2000 , manifested in an 
atypically high (or reduced) sensitivity when compared to years 1995 and 2007 (see Figure 16). This "abnormal" sensitivity to OPEC's and monetary exogenous factors occurs when the global economy is about to enter recession and the oil market is recovering from a crisis of prices. Anyway, the dynamic behavior of

the sensitivities of global consumption and accumulation are similar, even in atypical behavior or characteristic. This fact seems to assert the view of some authors (i.e. NORENG, 2002) who claim that oil accumulation (in its most typical form of stocks) can be considered as part of the demand, together with the consumption of oil.

\begin{tabular}{|c|c|c|c|c|c|c|c|}
\cline { 2 - 8 } \multicolumn{1}{c|}{} & \multicolumn{4}{c|}{ Exogenous Structural Factors } & Monetary \\
\cline { 2 - 8 } & \multicolumn{2}{|c|}{ Macroeconomic } & \multicolumn{2}{c|}{ OPEC's } & \multicolumn{2}{c|}{ OECD's } & $\begin{array}{c}\text { Exogenous } \\
\text { Factors }\end{array}$ \\
\cline { 2 - 7 } & GDP & DEF & CAP & PROD & RES & COST & $\in / \$$ \\
\hline $\begin{array}{c}\text { Endogen ous } \\
\text { Factors }\end{array}$ & $\begin{array}{c}\text { Strong } \\
\text { SpotWTI }\end{array}$ & $\begin{array}{c}\text { Slight } \\
\text { Decrease }\end{array}$ & $\begin{array}{c}\text { Slight } \\
\text { Growth }\end{array}$ & $\begin{array}{c}\text { Slight } \\
\text { Growth }\end{array}$ & $\begin{array}{c}\text { Strong } \\
\text { Decrease }\end{array}$ & $\begin{array}{c}\text { Strong } \\
\text { Decrease }\end{array}$ & $\begin{array}{c}\text { Very } \\
\text { Strong } \\
\text { Growth }\end{array}$ \\
\hline NonOPECProd & $\begin{array}{c}\text { Slight } \\
\text { Growth }\end{array}$ & $\begin{array}{c}\text { Slight } \\
\text { Growth }\end{array}$ & $\begin{array}{c}\text { Strong } \\
\text { Growth }\end{array}$ & $\begin{array}{c}\text { Strong } \\
\text { Growth }\end{array}$ & $\begin{array}{c}\text { Strong } \\
\text { Decrease }\end{array}$ & $\begin{array}{c}\text { Strong } \\
\text { Decrease }\end{array}$ & $\begin{array}{c}\text { Very } \\
\text { Strong } \\
\text { Growth }\end{array}$ \\
\hline
\end{tabular}

Figure 18 - Qualitative summary of test results in Figure 16 for oil prices and the production of non-OPEC countries

Source: Developed by the authors.

Note: There is an evolution qualitative descriptor (strong/slight growth, strong/slight decrease) for each pair (endogenous factor, exogenous factor), which describes the general trend of the impact of the exogenous factor (input) upon the endogenous factor (output) throughout the history (1995-2008).

The following observations and comments are drawn from the analysis of Figures 14, 15 and 16:

(1) Some endogenous factors show an atypically high level of sensitivity to RESERVES in 1995. This could be an erratic local behavior of model for this year, in view that sensitivities to RESERVES are almost negligible all over the rest of the period. A local resonance phenomenon can be suspected, considering the dynamic feedback nature of the model. However, a logical explanation to this behavior could be conceived, so that it might not be a problem of the model, but a market behavior detected by the model.

(2) By type, the structural factors that have greater impact on the global oil market are those for OPEC (production capacity and net production). This is clearly seen in the figures of Figure 15, when comparing the columns corresponding to average sensitivities. 
(3) ProdNoOPEP and SpotWTI sensitivities show similar dynamic behaviors when compared considering the exogenous financial $(\$ / €)$ and OPEC structural (Capacity, Production) factors; these factors are characterized by high uncertainty and relative independence of the other factors of the market.

(4) All exogenous variables are relevant to the model outputs at some point in the simulation, so that none could be dismissed as irrelevant.

(5) The size of the vertical scales of the graphs in Figure 15 indicates that some variables are less sensitive than others. Taking this benchmark into consideration, the price of crude SpotWTI is the most sensitive and volatile (2.5), while non-OPEC production would be the least sensitive (0.8), but the high impact upon this factor of the structural factors of OPEC (which have a large uncertainty) makes non-OPEC production difficult to predict, unlike global oil consumption, which, although it is more sensitive as judged by the size of the vertical scale (1.2), its sensitivity is mainly linked to changes in global GDP, which are by nature slow, small and predictable; hence, global consumption is a very rigid factor, and thus can be seen in the simulations. From the detailed study of the results for the sensitivity of the model, many other considerations are possible; some of them are the subject of ongoing investigation, and others could lead to further work.

\section{Final Considerations}

The importance of the GOM in the performance of the global economy makes this subject one of relevant importance. Hence, the numerous studies and models that attempt not only to describe and explain, but also to project the behavior of this market.

System dynamics models facilitate the understanding of complex systems and the analysis of multiple alternatives to compare results and choose the best. Hence, it seems to be a suitable tool for the study of the GOM.

Under the above considerations a model that simulates with reasonable accuracy the known past was designed and implemented; the model was subjected to a sensitivity study in order to assess the significance, relevance and impact of exogenous factors used, as well as the dynamic behavior of the model. The results of the sensitivity study enabled the evaluation of the dynamic behavior of the global oil market from the point of view of the interaction between various factors and agents, showing that the model replicates complex interactions that correspond to expected behaviors within the logic of the dynamics of that market. For example, the dynamic model is able to offer credible explanations regarding the interactions among market players that resulted in the soaring rise in oil prices in 2008, seeming to point out, for example, the irrelevance of structural factors in the development of this phenomenon. This allows us to infer the utility of the model in the analysis of complex GOM. 
Ongoing experimentation, in which the dynamic model is run within the context of future scenarios for the exogenous factors (beyond 2008) suggest the usefulness of the methodology for the forecast of the behavior of the GOM.

It is noteworthy that by its characteristics and way of being implemented, the proposed model can be easily extended for the consideration of additional exogenous factors, as well as simulations of the market under different architectures, such as the one that results of modifying the behavior of OPEC, from arbitrary to non-arbitrary or cooperative behavior.

\section{References}

BODENSTEIN, M.; ERCEG, C. J.; GUERRIERI, L. Oil shocks and external adjustment. Board of Governors of the Federal Reserve System (EUA), 2007. (International Finance Discussion Papers, 897).

CAMPOLMI, A. Oil price shocks: demand vs. Supply in a two-country model. 2008. (MNB Working Papers 2008/5).

CHANTZIARA, T.; SKIADOPOULOS, G. Can the dynamics of the term structure of petroleum futures be forecasted? Evidence from major markets. Energy Economics, v. 30, n. 3, p. 962-985, 2008.

DÉES, S. et al. Modeling the world oil market: Assessment of a quarterly econometric model. Energy Policy, v. 35, n. 1, p. 178-191, 2007.

FATTOUH, B. Analyzing oil prices: The usefulness and limitations of existing approaches. Presentation Prepared for The European Investment Bank. 25.01.2007. Centre for Financial and Management Studies, SOAS. University of London $\mathcal{E}$ Oxford. Institute for Energy Studies, 2007. Retrieved March15, 2008 from < http://www.oxfordenergy.org/presentations/analysing_oil_prices.pdf> .

FORRESTER, J. Dinámica Industrial. Buenos Aires: El Ateneo, 1972.

LAGARDA, L.; ALONSO, E. Modelos mentales y formales con dinámica de sistemas. 2001. Retrived November 30, 2007 from <ww.itson.mx/dii/elagarda/apagina2001/Dinamica/pdf/ caso-b.pdf $>$.

LIN, C. Y. C. Estimating and testing a dynamic model of OPEC and non-OPEC. Research Report UCD-ITS-RR-07-28, Institute of Transportation Studies, University of California, Davis, 2008.

MANERA M. et al. Evaluating the empirical performance of alternative econometric models for oil price forecasting. 2007. (Working Papers, n. 69. The Fondazione Eni Enrico Mattei) Retrieved March 19, 2008 from <http://www.feem.it/Feem/Pub/Publications/WPapers/default.htm>.

MOHADDES, K. Models of the Oil Market: Optimal Price and Output Paths. A literature survey. 2006. Econometrics Workshop (presentation as part of PhD research, University of Cambridge, UK).

MOSHIRI, S. FOROUTAN, F. Forecasting nonlinear crude oil futures prices. The Energy Journal, v. 27, p. 81-95, 2006.

NORENG, O. El poder del petróleo: la política y el mercado del crudo. Buenos Aires: El Ateneo, 2002.

PINDYCK R. S. The long-run evolution of energy prices. The Energy Journal, v. 20, n. 2, p. 1-27, 1999. 


\section{Appendix}
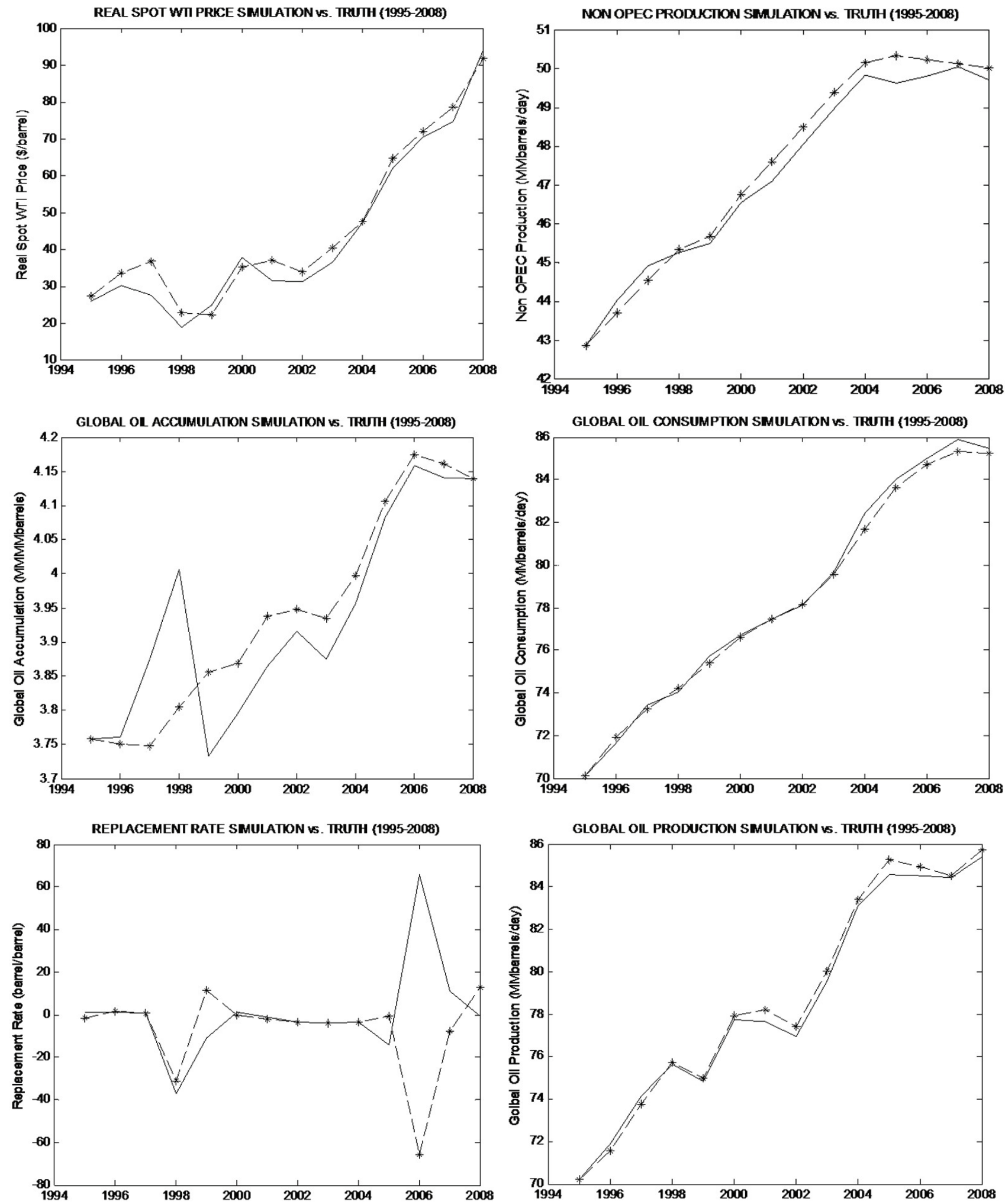

Figure 19 - Performance of the dynamic model as a GOM Simulator.

Historical series vs. simulations for the endogenous factors of the model, 1995-2008

Source: Developed by the authors.

Note: Continuous Lines $=$ Historical Truths; Dashed-dotted Lines $=$ Simulations .

Recebido em: 21/01/2011. Aceito em: 17/06/2011. 